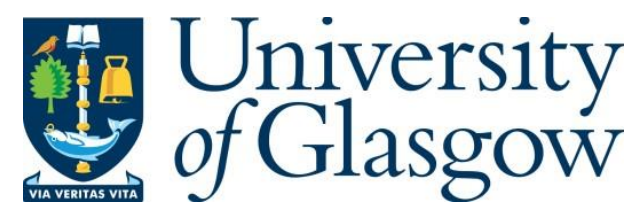

Berrones-Reyes, J. C., Muñoz-Flores, B. M., Uscanga-Palomeque, A. C., Santillán, R., Del Angel-Mosqueda, C., Nobis, D., Cochrane, M. A., Magennis, S. and Jiménez-Pérez, V. M. (2020) Two-photon detection of organotin Schiff base complexes in cancer cells. ChemistrySelect, 5(5), pp. 1623-1627.

There may be differences between this version and the published version. You are advised to consult the publisher's version if you wish to cite from it.

This is the peer reviewed version of the following article Berrones-Reyes, J. C., Muñoz-Flores, B. M., Uscanga-Palomeque, A. C., Santillán, R., Del Angel-

Mosqueda, C., Nobis, D., Cochrane, M. A., Magennis, S. and Jiménez-Pérez, V. M. (2020) Two-photon detection of organotin Schiff base complexes in cancer cells. ChemistrySelect, 5(5), pp. 1623-1627, which has been published in final form at http://dx.doi.org/10.1002/slct.201904816. This article may be used for noncommercial purposes in accordance with Wiley Terms and Conditions for SelfArchiving.

http://eprints.gla.ac.uk/210133/

Deposited on: 14 February 2019

Enlighten - Research publications by members of the University of Glasgow http://eprints.gla.ac.uk 


\section{Two-Photon Detection of Organotin Schiff Base Complexes in Cancer Cells}

Dr. Jessica C. Berrones-Reyes, ${ }^{a}$ Dr. Blanca M. Muñoz-Flores, ${ }^{a}$ Dr. Ashanti UscangaPalomeque, ${ }^{b}$ Prof. Rosa Santillán, ${ }^{c}$ Dr. Casiano Del Angel-Mosqueda, ${ }^{d}$ David Nobis, ${ }^{e}$ Max A. Cochrane, ${ }^{e}$ Dr. Steven W. Magennis, ${ }^{e} *$ Dr. Victor M. Jiménez-Pérez. ${ }^{a, *}$

${ }^{a}$ Universidad Autónoma de Nuevo León, Facultad de Ciencias Químicas, Av. Pedro de Alba, 66455, Nuevo León, México.

${ }^{\mathrm{b}}$ Universidad Autónoma de Nuevo León, Facultad de Ciencias Biológicas, Av. Pedro de Alba, 66455, Nuevo León, México.

${ }^{\mathrm{C}}$ Centro de Investigación y de Estudios Avanzados del IPN, Departamento de Química, A. P. 14740, C. P. 07000, D. F., México.

${ }^{\text {d} U n i v e r s i d a d ~ A u t o ́ n o m a ~ d e ~ N u e v o ~ L e o ́ n, ~ F a c u l t a d ~ d e ~ O d o n t o l o g i ́ a, ~ A v . ~ D r . ~ E d u a r d o ~ A g u i r r e ~}$ Pequeño, 64460, Nuevo León, México.

${ }^{\mathrm{e}}$ University of Glasgow, School of Chemistry, Joseph Black Building, University Pl, Glasgow G12 8QQ, United Kingdom.

*Corresponding authors: victor.jimenezpr@uanl.edu.mx, steven.magennis@glasgow.ac.uk

Keywords: Organotin, fluorescent bioimaging, cancer detection, two-photon excitation. 
ABSTRACT The early detection of cancer cells and their visualisation before and after surgery are essential for successful pre- and post-operative disease management. Although fluorescence imaging is a sensitive and versatile tool that is finding increasing use in clinical applications, there is a lack of tumour-targeting fluorophores. We report here a family of fluorescent Schiff base

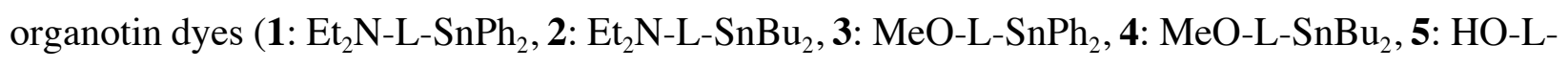
$\mathrm{SnPh}_{2}$, and 6: $\mathrm{HO}-\mathrm{L}-\mathrm{SnBu}_{2}$, where $\mathrm{L}=$ 2-hydroxybenzylidene-4-hydroxybenzhydrazine). In addition to one-photon-excited fluorescence, efficient two-photon excitation was demonstrated in compounds 1-4. Two of the compounds (5 and 6), both with hydroxyl substituents, were capable of selective accumulation in HeLa cells, allowing differentiation from normal cells (periodontal ligament cells). Compounds $\mathbf{1}$ and $\mathbf{3}$ showed excellent cancer cell staining (HeLa) using twophoton bioimaging which is promising for biomedicine applications.

\section{Introduction}

The use of contrast markers for the detection of cancer cells is an attractive approach to improve the management of this disease. ${ }^{[1]}$ The main goal in this field is to develop tumor-imaging agents that can be selective to target cells. ${ }^{[2]}$ In cancer diagnosis, the early identification of cell abnormalities significantly reduces the mortality rate. Fluorescence imaging has proved to be an important tool with clinical applications, due to advantages such as high sensitivity and

versatility. ${ }^{[3-6]}$ Resection surgery is the gold standard treatment for most solid tumors, and the fluorescent probes have been used to enhance structural differences between normal and cancer cells. The presence of remaining transformed cells in the tumor margins after surgical treatment is usually considered one of the strongest predictors of tumor recurrence and survival. ${ }^{[7]}$ In recent 
decades, a range of fluorescent materials have been proposed as imaging probes for cancer diagnosis, including nanoparticles, ${ }^{[8,9]}$ quantum dots,${ }^{[10]}$ and organometallic molecules. ${ }^{[11,12]}$

An important difference between many tumors and normal tissues is the nutritional and metabolic environment. The production of lactic acid under anaerobic conditions and the hydrolysis of ATP in an energy-deficient environment contribute to the acidic microenvironment which has been found in several tumor types. ${ }^{[13]}$ In this context, $\mathrm{pH}$ differences have been the basis of cancer treatments and probes for diagnosis. ${ }^{[14]}$ The modulation of the fluorescent properties can also be influenced by other external factors such as viscosity and temperature. ${ }^{[15-17]}$ Recently, biologicallyactive compounds derived from Schiff base molecules have shown promise as fluorescent reporters. ${ }^{[18,19]}$ These molecules possess the azomethine fragment $(-\mathrm{N}=\mathrm{CH})$, which is the key to the design of new drugs with anti-convulsant, anti-depressant, analgesic, anti-inflammatory, and anti-malarial activity. The generation of Schiff base derivatives with high thermal stability to air and moisture as well as diverse biological activity have been reported. ${ }^{[20,21]}$ The structural diversity of the organotin compounds derived from Schiff bases, and their applications, have been a major impetus for the investigation of these molecules. ${ }^{[22,23]}$ Recently, we reported luminescent organotin derivatives and their application in bioimaging studies. ${ }^{[24,25]}$ Here we show that a family of organotin compounds have attractive fluorescent properties, via one-photon (1P) and two-photon (2P) excitation, and that they can selectively penetrate and stain cancer cells and be differentiated from normal cells.

\section{Results and Discussion}

Synthesis and characterization. The one-pot reaction of a 5-substituted salicylaldehyde derivative, 4-hydroxy-benzoylhydrazine and the corresponding diorganotin oxide afforded the 
pentacoordinated organotin derivatives (1-6) in yields from 55 to $95 \%$ as yellow solids (Scheme 1). The ${ }^{119} \mathrm{Sn}$ NMR spectra of dibutyltin derivatives $(\mathbf{2}, \mathbf{4}$, and $\mathbf{6})$ show a single resonance within the range of -194.4 to $-198.6 \mathrm{ppm}$, while in the diphenyl tin complexes $(\mathbf{1}, \mathbf{3}$, and $\mathbf{5})$ this is shifted to -331.3 to $-336.5 \mathrm{ppm}$. The ${ }^{13} \mathrm{C}$ NMR spectra $\left(\mathrm{CD}_{3} \mathrm{OD}\right)$ for all of the organotin compounds (16) exhibited the $\delta$ of imine carbons (C-7) in the range of 160.24 to $161.55 \mathrm{ppm}$ (Table 1). The signals assigned to the azomethine protons (H-7) in the ${ }^{1} \mathrm{H}$ NMR spectra appear in the range of 8.45-8.66 ppm and the ${ }^{3} J\left({ }^{1} \mathrm{H}-\mathrm{N}-{ }^{119} \mathrm{Sn}\right)$ from 40.9 to $57.6 \mathrm{~Hz}$, confirming the presence of $\mathrm{N} \rightarrow \mathrm{Sn}$ coordination bonds, which is in agreement with previous reports. ${ }^{[26]}$ Elemental analyses of the compounds were difficult to obtain but the high-resolution mass spectra were in good agreement.

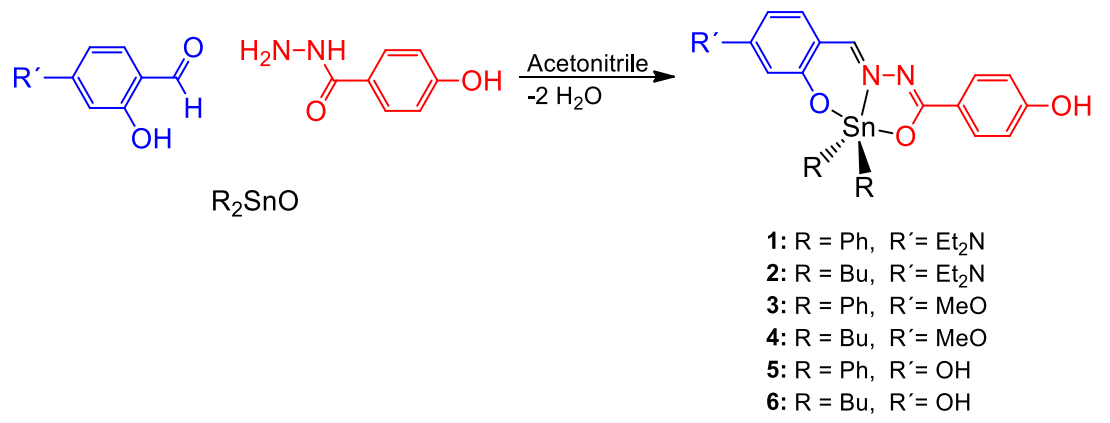

Scheme 1. Synthesis of organotin compounds 1-6.

Table 1. Selected ${ }^{1} \mathrm{H},\left({ }^{\mathrm{n}} \mathrm{J}^{1} \mathrm{H}_{-}{ }^{119} \mathrm{Sn}\right)$, and ${ }^{119} \mathrm{Sn}(\mathrm{ppm})$.

\begin{tabular}{llllllll}
\hline Comp. & ${ }^{1} \mathbf{H}$ & ${ }^{13} \mathbf{C}$ & & & & \multicolumn{1}{l}{ Sn } \\
& H-7 & C-7 & C- $\alpha / \mathbf{C}_{\mathbf{i}}$ & $\mathbf{C - 1}$ & $\mathbf{C - 8}$ & \\
\hline $\mathbf{1}$ & $8.48[57.6]$ & 160.51 & 140.94 & 170.08 & 168.56 & -331.35 \\
$\mathbf{2}$ & $8.45[46.8]$ & 160.24 & 22.47 & 169.49 & 169.34 & -194.41 \\
$\mathbf{3}$ & $8.66[54.7]$ & 161.55 & 140.92 & 170.75 & 170.07 & -336.54 \\
$\mathbf{4}$ & $8.62[40.9]$ & 161.26 & 22.87 & 170.31 & 170.27 & -198.64 \\
$\mathbf{5}$ & $8.63[54.8]$ & 161.46 & 140.68 & 170.75 & 169.58 & -335.50 \\
& & & & & & \\
\hline
\end{tabular}




\begin{tabular}{lllllll}
\hline 6 & $8.57[43.6]$ & 161.38 & 22.75 & 170.17 & 170.11 & -197.88
\end{tabular}

The single crystal X-ray diffraction structure of $\mathbf{5}$ is represented by the thermal ellipsoid plots in Figure 1 (see Table S1 for details). The crystal structure shows a planar skeleton array with a pentacoordinated tin atom and with N-Sn coordination bond length of 2.1459(18) A. The C-C bond lengths of the aromatic systems correspond to the data previously reported for similar molecules. ${ }^{[27]}$ The tin atom adopts a distorted trigonal bipyramid geometry. The X-ray diffraction structure of 4 shows a similar coordination number in the tin atom as well as the planar skeleton array. Additionally, compound 4 shows intermolecular $\pi$-stacking (Figures S1 and S2).

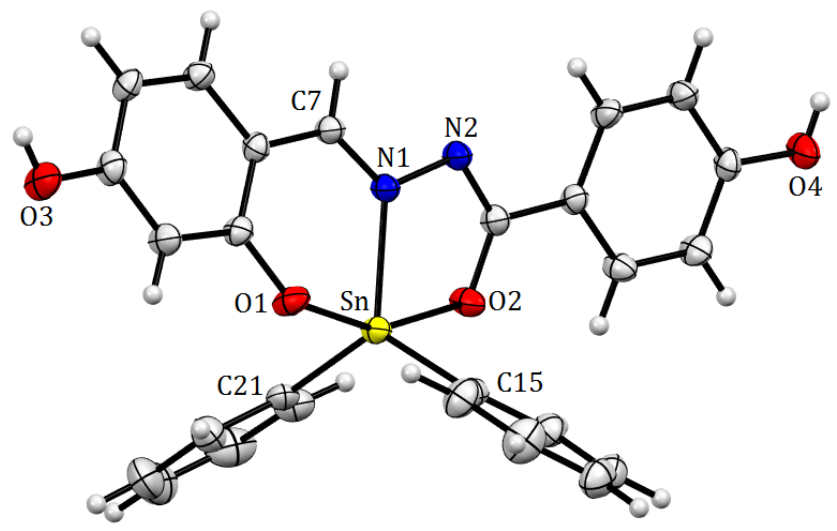

Figure 1. Crystal X-ray structure of compound 5. Selected bond distances: Sn-O1 2.0697(15), Sn-O2 2.1342(15), Sn-N1 2.1459(18), Sn-C16 2.107(2), Sn-C15 2.119(2), and N1-C7 1.293(3) A. Selected angles: O1-Sn-O2 156.41(7), C15-Sn-C16 125.32(9), N1-Sn-O2 72.88(6), N1-Sn-O1 $83.60^{\circ}(6)$

Photophysical characterization. The 1P photophysical properties of the six compounds were studied in ethanol, DMSO, and DMF solutions. Steady-state absorption and emission for a particular sample are similar in each solvent (Figures S3-S8). In general, all of the compounds 
exhibit a main absorption peak in the visible, with maximum wavelength ranging between 398 and $446 \mathrm{~nm}$, which is attributed to $\pi-\pi^{*}$ transitions (Figure 2a and Figures S3-5). The position of the maximum absorption band depends on the Schiff base substituent; those with the diethylamine group (1 and 2) are red shifted when compared to the other compounds, which have methoxy and hydroxy groups. Compounds $\mathbf{1}$ and $\mathbf{2}$ are noticeably red-shifted and have a structured absorption band in each solvent with peak separation of $\sim 1100 \mathrm{~cm}^{-1}$. ${ }^{[28]}$
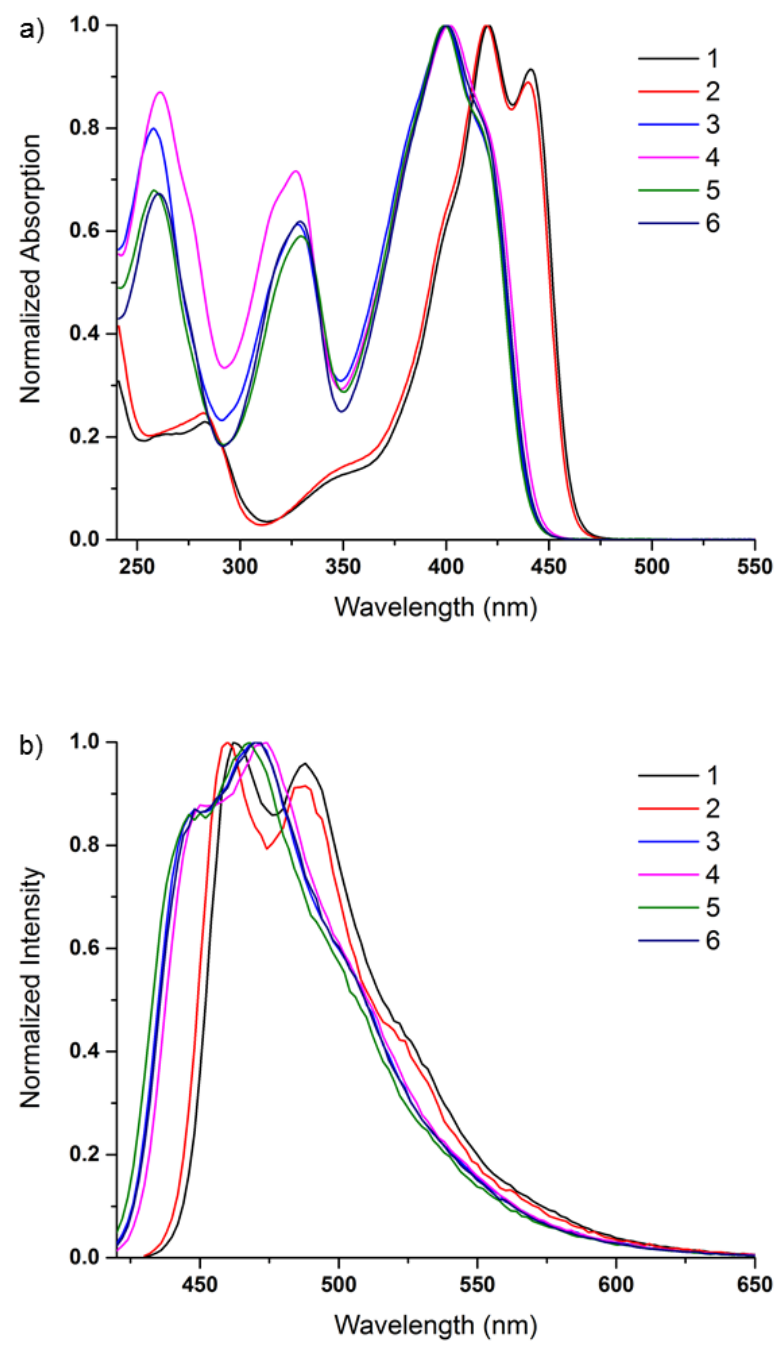
Figure 2. Electronic absorption spectra (a) and 1P emission spectra (b) of compounds 1-6 in methanol. See SI for spectra in ethanol, DMF, and DMSO.

The emission is most intense between 450-500 nm (Figure $2 \mathrm{~b}$ and Figures S6-8). 1 and $\mathbf{2}$ are distinct from the other four compounds, with a red-shifted structured emission, with separation in peaks of $\sim 1100 \mathrm{~cm}^{-1}$, similar to the peak separation in the absorption spectra. The absorption and emission spectra for compounds 3-6 are qualitatively similar to $\mathbf{1}$ and $\mathbf{2}$, but display a peak and shoulder rather than two distinct peaks. We attribute the peaks in the absorption and emission spectra of 1-6 to vibronic transitions. The fluorescence quantum yields for 1-6 range from 13-34\% (Table 2 and Tables S2-4). They are relatively independent of the solvent and are highest for $\mathbf{3}$ and 4. We attribute the longest wavelength absorption and emission peaks to $\pi-\pi^{*}$ transitions, which agrees with the observed extinction coefficients. The quantum yields compare favourably with similar pentacoordinated tin compounds derived from Schiff bases. ${ }^{[29]}$

The 1P fluorescence lifetimes were measured using time-correlated single-photon counting (TCSPC). Compounds 1-4 followed monoexponential kinetics in all solvents (Table 2 and Tables S2-4). Compound 6 displayed monoexponential kinetics in methanol, ethanol, and DMF but biexponential kinetics in DMSO, while 5 displayed biexponential kinetics in DMF and DMSO. The general trend in each solvent was that 1-4 had lifetimes that were similar to each other (ranging from 1.7- $2.0 \mathrm{~ns}$ ) but longer than 5 and $\mathbf{6}$ (1.5-1.8 ns). For $\mathbf{5}$ in DMF and DMSO, the longer lifetime component is similar (1.7 ns) to the lifetime observed in methanol and ethanol and accounts for $60 \%$ of the population; the shorter component is $0.19 \mathrm{~ns}$ in DMF and $0.28 \mathrm{~ns}$ in DMSO. Interestingly, although the fit to a single exponential decay in DMSO for 5 is very poor $\left(\chi^{2} \sim 24\right)$, the incremental addition of water results in a concomitant increase in the population of the longer 
lifetime component, so that after only $2 \% \mathrm{v} / \mathrm{v}$ water addition the lifetime is single exponential with a lifetime of $1.69 \mathrm{~ns}\left(\chi^{2}=1.01\right)$. For 6 in DMSO, the major component $(84 \%)$ is similar to the lifetime in the other solvents $(1.7 \mathrm{~ns})$, while the short component is $0.62 \mathrm{~ns}$. As for $\mathbf{5}$, the data cannot be fitted to a single exponential decay in pure $\operatorname{DMSO}\left(\chi^{2} \sim 3\right)$, but an addition of $10 \%$ water results in a monoexponential decay with a lifetime of $1.67 \mathrm{~ns}\left(\chi^{2}=1.03\right)$. Similar behaviour is observed for 5 in DMF, where the lifetime is essentially monoexponential $\left(\chi^{2}=1.19\right)$ with a lifetime of 1.59 ns after addition of $10 \%$ water. The lifetimes of $\mathbf{5}$ and $\mathbf{6}$ in DMSO/DMF in the presence of water are similar to those measured in methanol and ethanol. Therefore, we attribute them to interactions between the hydroxyl on R' (Scheme 1) and the polar protic solvents.

Table 2. Photophysical parameters for compounds 1-6 in methanol. ${ }^{[a]}$

\begin{tabular}{lccccccc}
\hline Comp. & $\lambda_{\max }^{[\mathrm{bl}]}[\mathrm{nm}]$ & $\varepsilon^{[\mathrm{cc}]}$ & $\lambda_{\mathrm{em}}[\mathrm{nm}]^{[\mathrm{d}]}$ & $\Phi[\%]^{[\mathrm{e}]}$ & $\tau[\mathrm{ns}]^{[\mathrm{f}]}$ & $\chi^{[\mathrm{gg}]}$ & $\sigma^{2[\mathrm{~h}]}[\mathrm{GM}]$ \\
\hline $\mathbf{1}$ & 421,441 & 3.51 & 462,488 & 16 & 1.94 & 0.98 & 50 \\
$\mathbf{2}$ & 421,440 & 3.67 & 460,488 & 16 & 1.86 & 0.97 & 48 \\
$\mathbf{3}$ & 328,400 & 2.25 & 448,470 & 27 & 1.67 & 1.04 & 3.5 \\
$\mathbf{4}$ & 327,401 & 2.39 & 450,472 & 27 & 1.75 & 1.00 & 5.5 \\
$\mathbf{5}$ & 330,400 & 2.06 & 450,468 & 22 & 1.46 & 1.03 & - \\
$\mathbf{6}$ & 329,401 & 2.89 & 448,470 & 22 & 1.53 & 1.02 & - \\
\hline
\end{tabular}

[a] See SI for experimental details and for data in ethanol, DMSO and DMF. [b] Absorption maxima. [c] Extinction coefficient at longest wavelength maxima in units of $104 \mathrm{M}-1 \mathrm{~cm}-1$.[d] Emission maximum. [e] Emission quantum yield (excited at $366 \mathrm{~nm}$ ). [f] Fluorescence lifetime (excited at $430 \mathrm{~nm}$ ). [g] singleexponential decay fit parameter. [h] Two-photon cross section. The accuracy of the measurements was estimated to be $\pm 20 \%$. 
In addition to studying the $1 \mathrm{P}$ fluorescence properties, we investigated the potential for $2 \mathrm{P}$ activation of fluorescence. 2P microscopy could offer advantages such as 3D control of excitation, deep tissue penetration, and reduced photobleaching. ${ }^{[30]}$ We studied compounds 1-4 in methanol and found that they could all undergo $2 \mathrm{P}$ excitation. The $2 \mathrm{P}$ emission spectra were the same as those measured via 1P excitation (Figure 3a). The log-log plots of emission intensity versus power confirm a $2 \mathrm{P}$ process (Figure $3 \mathrm{~b})$. The $2 \mathrm{P}$ cross sections (Table 1) are $\sim 50 \mathrm{GM}\left(\mathrm{GM}=10^{-50} \mathrm{~cm}^{4} \mathrm{~s}\right.$ photon $^{-1}$ ) for $\mathbf{1}$ and $\mathbf{2}$ and $\sim 5$ GM for $\mathbf{3}$ and $\mathbf{4}$, following excitation at $800 \mathrm{~nm}$, which is close to double the 1P absorption maxima (Figure 2). These $2 \mathrm{P}$ cross sections are consistent with those of other organotin complexes. ${ }^{[31,32]}$ It is noteworthy that when organotin compounds are linked to the $\mathrm{Et}_{2} \mathrm{~N}$ - groups, the $\mathrm{GM}$ values are higher than the $\mathrm{MeO}$ - groups.

a)

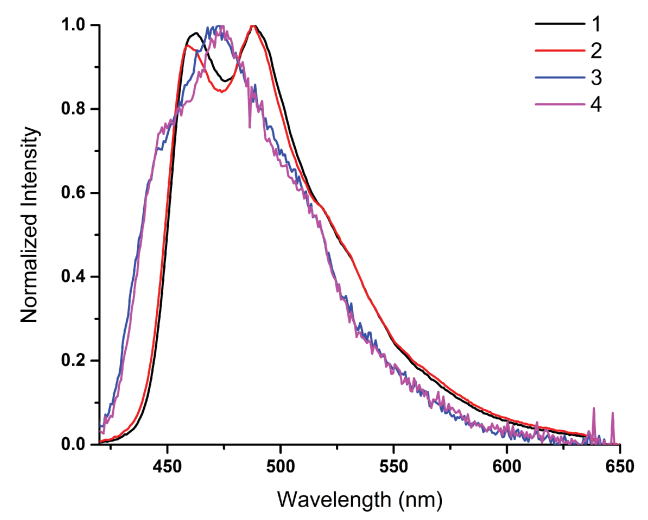

b)

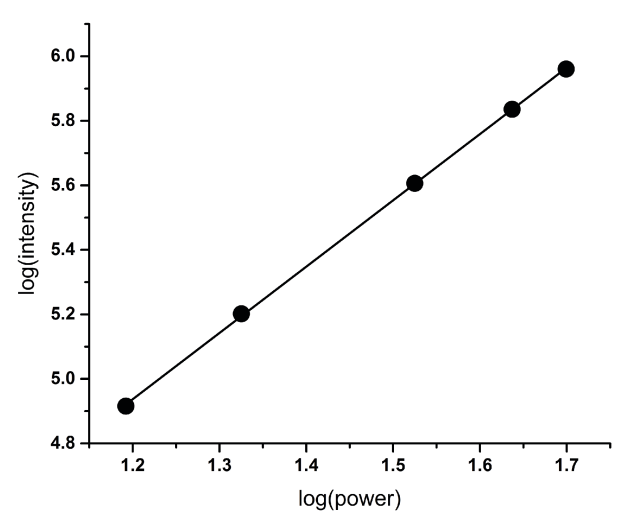


Figure 3. 2P excitation of organotin complexes. (a) Emission spectra of 1-4 in methanol (excited at $800 \mathrm{~nm}$ with $10 \mathrm{~nm}$ FWHM). (b) Power dependence of $\mathbf{1}$ in methanol. The slope is 2.05(1) indicating a $2 \mathrm{P}$ process.

Fluorescence bioimaging. We next investigated the biological interaction of organotin compounds (see SI for experimental details). 1P fluorescence microscopy was used to performed experiments on periodontal ligament cells (PDLCs) and HeLa cells. After isolation and primary culture, PDLCs showed a typical fibroblastic-elongated morphology and tended to align themselves in parallel lines. A polygonal-shaped cell appearance was observed in HeLa cells after incubation. Some morphological differences in both cell types were detected, such as length, shape, and size (Figure 4). 


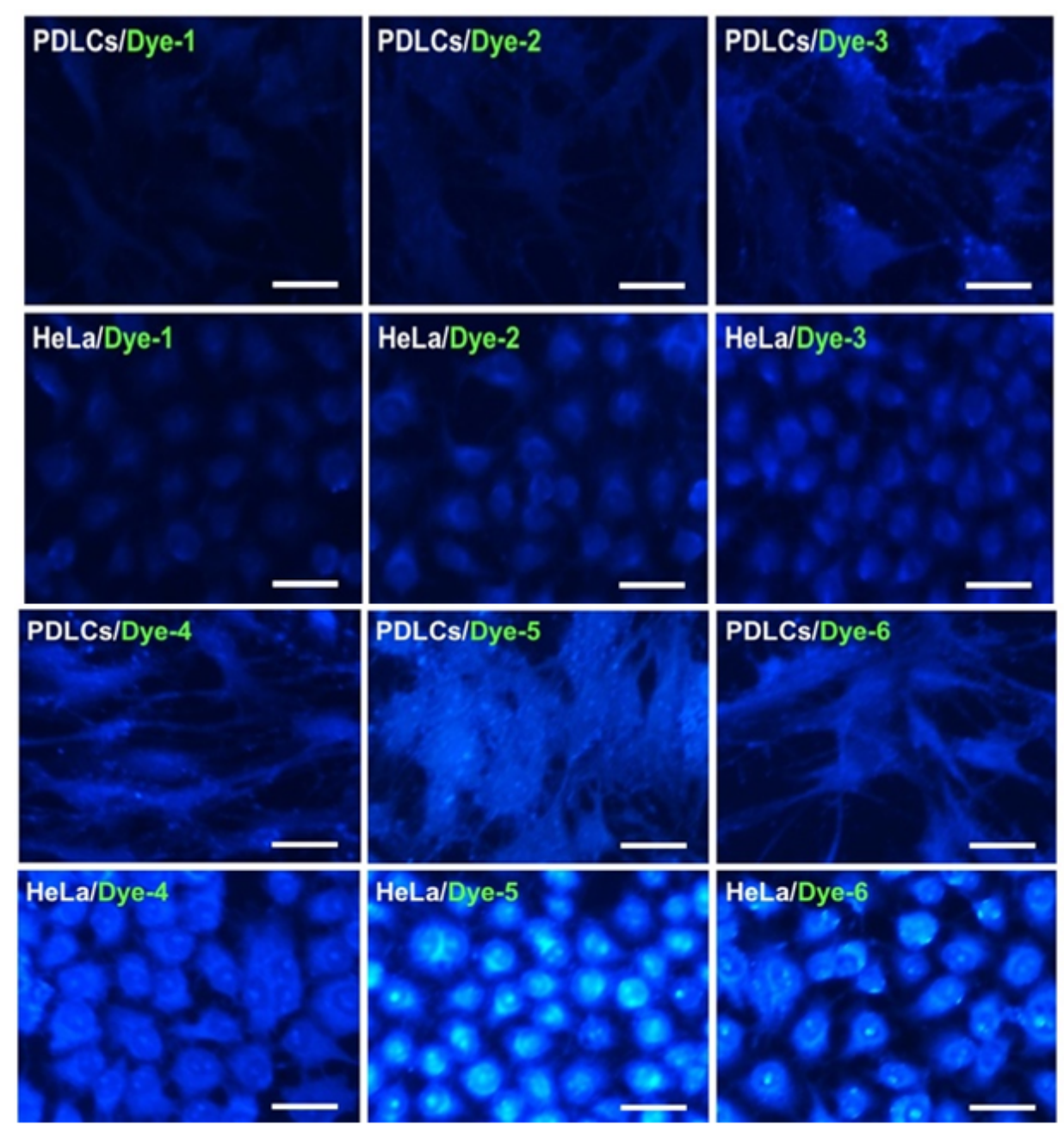

Figure 4. Biological activity of organotin compounds 1-6 was analyzed by 1P fluorescence microscopy on PDLCs and HeLa cells. Representative images from cells incubated with the organotin dyes are shown. Emission was detected in both cell types, however, for the compounds $\mathbf{1}, \mathbf{2}$, and $\mathbf{3}$, a significant difference in the fluorescence intensity was not detected. The HeLa cells treated with 5 and 6, showed a strong-bright emission intensity located in the nucleoli and ribosomes. All molecules were excited in the UV region (360-370 nm) and detected in the range 420-460 nm. Original magnification 20x, scale bar $=50 \mu \mathrm{m}$.

After exposure to organotin compounds for $10 \mathrm{~min}$, the cytoplasmic content of PDLCs and HeLa cells exhibited fluorescence (detected from 420-460 nm) after excitation in the region 360-370 nm, 
indicating that all six organotin complexes are capable of binding to mammalian cells. A moderate fluorescence was observed in cells treated with the dyes 1, 2, 3, and 4; however, in the HeLa cells stained with the organotin compounds $\mathbf{5}$ and $\mathbf{6}$, a stronger fluorescence was observed, which was more localized in the cytoplasm, nucleoli and ribosomes in comparison with the PDLCs (Figure 4). It is known that the morphological and functional modifications in the nucleolus, widely observed in tumor cells, are accompanied by a significant increase in the synthesis of proteins related to cell cycle regulation and ribosome biogenesis, which characterizes proliferating cells. ${ }^{[33,34]}$ As shown above, $\mathbf{5}$ and $\mathbf{6}$ can exist in, at least, two states. The bright state is associated with protonation of the hydroxyl group. Therefore, we hypothesise that the selectivity for cancer cells is due to the interaction between the hydroxyl groups of these organotin probes and upregulated ribosomal proteins or overexpressed RNA. ${ }^{[35]}$ A previous study of the bioaccumulation of organotin compounds gave evidence of binding to sulfhydryl groups on proteins. ${ }^{[36]}$ Therefore, a dependence of fluorescence intensity on the HeLa cell cycle machinery could occur via increased binding of the organotin compounds to proteins and RNA, due to the overexpression of nearly 2000 genes in HeLa cells. These genes are related to cell cycle phase and transcription processes. ${ }^{[37]}$

Given the promising two-photon cross sections measured for compounds 1-4 in solution (see above), we then conducted a preliminary investigation of two of the compounds ( $\mathbf{1}$ and $\mathbf{3})$ for twophoton imaging inside cells. Two-photon excitation in HeLa cells was accomplished by using multiphoton microscopy with excitation at $842 \mathrm{~nm}$, which is close to double the $1 \mathrm{P}$ absorption maxima. High-resolution images of the cells were generated by raster scanning of the laser spot in the xy plane. The images clearly confirm the preferential localization of organotin compounds 1 and $\mathbf{3}$ in the cytoplasm that had been observed in the confocal experiments described above. The results demonstrate the viability of TPE of complexes $\mathbf{1}$ and $\mathbf{3}$ in live cells (Figure 5). The 
fluorescent bioimaging of other organotin carboxylate complexes have shown promise recently, ${ }^{[38,}$ ${ }^{39]}$ so this will be an area that we will explore in the future. Additionally, organotin compounds as a fluorescent probe in vitro have been shown to have over $80 \%$ cellular viability. ${ }^{[24]}$

a)

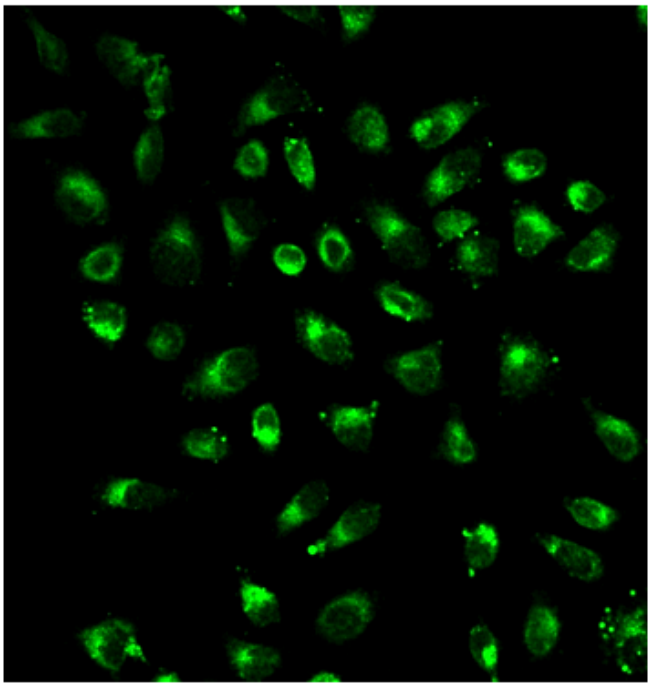

b)

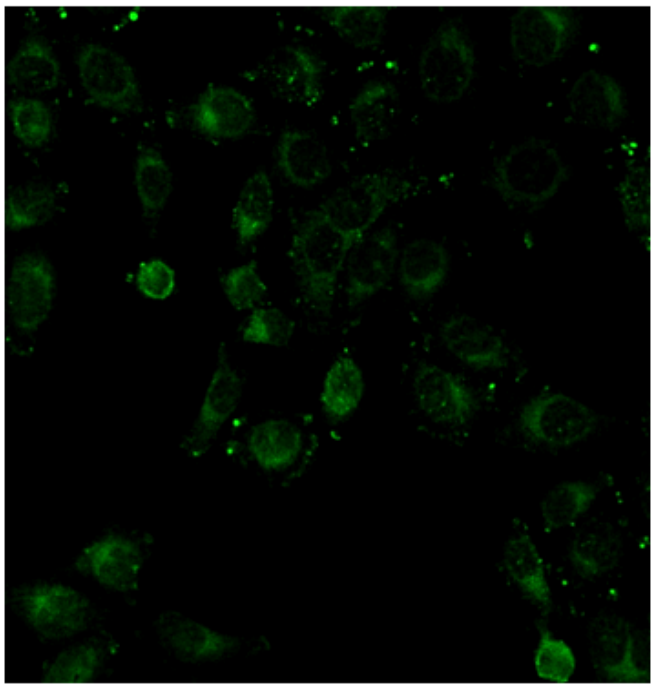

Figure 5. HeLa cells stained with $5 \mathrm{mM}$ of organotin compounds $\mathbf{1}$ (a) and $\mathbf{3}$ (b), visualized by $2 \mathrm{P}$ microscopy (excitation at $842 \mathrm{~nm}$ ). Results shown are representative of triplicates of three independent experiments.

\section{Conclusions}

In summary, we have presented a series of novel fluorescent Schiff base organotin derivatives for applications as bioimaging probes; in particular, $2 \mathrm{P}$ excitation was demonstrated in solution and cells. The compounds with hydroxyl substituents were able to selectively stain one cancer cell line (HeLa), which we hypothesise is due to specific interactions with up-regulated products, though proof of this will require further study. We plan to extend this approach to probe over 
expression in other cancer cell lines and to investigate the use of the Schiff bases as tumor-targeted diagnostics. ${ }^{[40]}$

\section{Supporting Information Summary}

Experimental details; ${ }^{1} \mathrm{H},{ }^{13} \mathrm{C}$ and ${ }^{119} \mathrm{Sn}$ NMR spectra; high-resolution mass spectra; X-ray structure for compound 4; crystallographic data for 4 and 5; and photophysical properties of compounds 16 in ethanol, DMF and DMSO.

\section{Accession Codes}

CCDC 1827951 and 1827950 for compounds $\mathbf{4}$ and $\mathbf{5}$ respectively contain the supplementary crystallographic data for this paper. These data can be obtained free of charge via www.ccdc.cam.ac.uk/data_request/cif, or by emailing data_request@ccdc.cam.ac.uk, or by contacting The Cambridge Crystallographic Data Centre, 12 Union Road, Cambridge CB2 1EZ, UK; fax: +44 1223336033.

\section{Author Information}

Corresponding Authors

*E-mail:victor.jimenezpr@uanl.edu.mx, Steven.Magennis@glasgow.ac.uk

\section{ORCID}

Steve Magennis: 0000-0002-4327-8366

Víctor M. Jiménez Pérez: 0000-0003-4306-2482

Notes 
The authors declare no competing financial interest

\section{Acknowledgements}

The authors thank CONACYT (grant: 240011). J. C. Berrones-Reyes thanks to CONACYT for the Ph. D. scholarship and also D. Nobis thanks EPSRC for a studentship. We thank Raul BerrocalMartin for assistance with TCSPC measurements.

\section{References}

[1] D. J. Pierce, J. R. Richards-Kortum, Int. J. Cancer 2008, 123, 1979-1990.

[2)] N. Jiang, J. Fan, F. Xu, X. Peng, H. Mu, J. Wang, X. Xiong, Angew. Chem. Int. Ed. 2015, 54, $2510-2514$.

[3] W. Xu, Z. Zeng, J.-H. Jiang, Y.-T. Chang, L. Yuan, Angew. Chem. Int. Ed. 2016, 55, 1365813699.

[4] O. S. Wolfbeis, Chem. Soc. Rev. 2015, 44, 4743-4768.

[5] F. Leblond, S. Davis, P. A. Valdés, B. W. Pogue, J Photochem. Photobiol. B 2010, 98, 77-94.

[6] S. Yao, X. Zhang, H. Wang, H. Wang, X. Gan, Z. Wu, Y. Tian, Z. Pan, H. Zhou, Dyes Pigm. 2017, $145,152-159$.

[7] Q. T. Nguyen, R. Y. Tsien, Nat Rev Cancer 2013, 13, 653-662.

[8] L. Shang, S. Dong, G. U. Nienhaus, Nano Today 2011, 6, 401-418.

[9] Y. Kang, Y. Z. Wu, X. Hu, X. Xu, J. Sun, R. Geng, T. Huang, X. Liu, Y. Ma, Y. Chen, Q. Wan, X. Qi, G. Zhang, X. Zhao, X. Zeng, Sci. Rep. 2017, 7, 45313.

[10] F. Erogbogbo, K.-T. Yong, I. Roy, G. Xu, P. N. Prasad, M. T. Swihart, ACS Nano 2008, 2, 873-878. 
[11] S. Luo, E. Zhang, Y. Su, T. Cheng, C. Shi, Biomaterials 2011, 32, 7127-38.

[12] J. P. Weichert, P. A. Clark, I. K. Kandela, A. M. Vaccaro, W. Clarke, M. A. Longino, A. N.

Pinchuk, M. Farhoud, K. I. Swanson, J. M. Floberg, J. Grudzinski, B. Titz, A. M. Traynor, H. Chen, L. T. Hall, C. J. Pazoles, P. J. Pickhardt, J. S. Kuo, Sci. Transl. Med. 2014, 6, 240-75.

[13] I. F. Tannock, D. Rotin, Cancer Research 1989, 49, 4373-4384.

[14] J. R. Griffiths, Br. J. Cancer 1991, 64, 425-427.

[15] J. E. Blatt, F. E. Treloar, K. P. Ghiggino, R. G. Gilbert, J. Phys. Chem. 1981, 85, 2810-2816.

[16] M. Baruah, W. Qin, C. Flors, J. Hofkens, R. A. Vallée, D. Belionne, M. Van der Auweraer, W. M. De Borggraeve, N. Boens, J. Phys. Chem. A. 2006, 110, 5998-6009.

[17] S. Sharafy, K. A. Muszka, J. Am. Chem. Soc. 1971, 93, 4119-4125.

[18] M. Ibarra-Rodríguez, B. M. Muñoz-Flores, H. V. Rasika Dias, M. Sánchez, A. GómezTreviño, R. Santillán, N. Farfán, V. M. Jiménez-Pérez, J. Org. Chem. 2017, 82, 2375-2385.

[19] H. Wang, B. Fang, L. Kong, X. Li, Z. Feng, Y. Wu, K. Uvdal, Z. Hu, Spectrochim. Acta A Mol. Biomol. Spectrosc. 2018, 198, 304-308.

[20] L. X. Cheng, J. J. Tang, H. Luo, X. L. Jin, F. Dai, J. Yang, Y. P. Qian, X. Z. Li, B. Zhou, Bioorganic Med. Chem. Lett. 2010, 20, 2417-2420.

[21] P. Raj, A. Singh, A. Singh, N. Singh, ACS Sustainable Chem. Eng. 2017, 5, 6070-6080.

[22] E. Guzmán-Percástegui, J. G. Alvarado-Rodríguez, J. Cruz-Borbolla, N. Andrade-López, R. A. Vázquez-García, R. N. Nava- Galindo, T. Pandiyan, Cryst. Growth Des. 2014, 14, 3742-3757. [23] H. D. Yin, J.-C. Cui, Y.-L.Qiao, Polyhedron 2008, 27, 2157-2166.

[24] V. M. Jiménez-Pérez, M. C. García-López, B. M. Muñoz-Flores, R. Chan-Navarro, J. C. Berrones-Reyes, H. V. Rasika Dias, I. Moggio, E. Arias, J. A. Serrano-Mireles, A. Chavez-Reyes, J. Mater Chem B 2015, 3, 5731-5745. 
[25] B. M. Muñoz-Flores, J. Cabrera, A. Chávez-Reyes, H. V. Rasika Dias, C. Viñas, V. M. Jiménez-Pérez, R. Nuñez, Chem. Eur. J. 2018, 24, 5601-5612.

[26] N. Kobakhidze, N. Farfán, M. Romero, J. M. Méndez-Stivalet, M. G. Ballinas-López, H. García-Ortega, O. Domínguez, R. Santillán, F. Sánchez-Bartez, I. Gracia-Mora, J. Organomet. Chem. 2010, 695, 1189-1199.

[27] K. M. Chow, K. M. Lo, Polyhedron 2014, 81, 370-381.

[28] H. D. Yin, S. W. Chen, J. Organomet. Chem. 2006, 691, 3103-3110.

[29] M. García-López, B. Muñoz-Flores, V. M. Jiménez-Pérez, I. Moggio, E. Arias, R. ChanNavarro, R. Santillan, Dyes Pigm. 2014, 106,188-196.

[30] W. R. Zipfel, R. M. Williams, W. W. Webb, Nat. Biotechnol. 2003, 21, 1369-1377.

[31] A. Enríquez-Cabrera, A. Vega-Peñaloza, V. Álvarez-Venicio, M. Romero-Ávila, P. G. Lacroix, G. Ramos-Ortiz, R. Santillan, N. Farfán, J. Organomet. Chem. 2018, 855, 51-58.

[32] H. Wang, L. Hu, W. Du, X. Tian, Q. Zhang, Z. Hu, L. Luo, Z. Zhou, J. Wu, Y. Tian, Y. ACS Biomater. 2017, 3, 836-842.

[33] L. Montanaro, D. Treré, M. Derenzini, Am. J. Pathol. 2008, 173, 301-310.

[34] J. Pelletier, G. Thomas, S. Volarević, Nat. Rev. Cancer. 2018, 18, 51-63.

[35] H. M. Wahba, M. J. Stevenson, A. Mansour, J. Sygusch, D. E. Wilcox, J. G. Omichinski, J. Am. Chem. Soc. 2017, 139, 910-921.

[36] F. Arjmand, I. Yousuf, Y. Zaidi L. Toupet, RSC Adv. 2015, 5, 16250-16264.

[37] J. J. Landry, P. T. Pyl, T. Rausch, T. Zichner, M. M. Tekkedil, A. M. Stutz, A. Jauch, R. S. Aiyar, G. Pau, N. Delhomme, J. Gagneur, J. O. Korbel, W. Huber, L. M. Stenmetz, G3 (Bethesda) 2013, 3, 1213-1224. 
[38] Q. Zhang, M. Zhang, H. Wang, X. Tian, W. Ma, L. Luo, J. Wu, H. Zhou, S. Li, Y. Tian, J. Inorg. Biochem. 2019, 192, 1-6

[39] L. Hu, H. Wang, T. Xia, B. Fang, Y. Shen, Q. Zhang, X. Tian, H. Zhou, J. Wu, Y. Tian, Inorg. Chem. 2018, 57, 6340-6348

[40] P. S. Low, S. Singhal, M. Srinivasarao, Curr. Opin. Chem. Biol. 2018, 45, 64-72. 


\section{Table of contents}

We report the synthesis of a family of fluorescent organotin Schiff bases and demonstrate bright emission via one-photon and two-photon excitation. Two compounds, with hydroxyl substituents, were capable of selective accumulation in HeLa cells, allowing differentiation from normal cells (periodontal ligament cells). We also report a proof-of-principle demonstration of cancer cell staining (HeLa) using two-photon bioimaging, which is promising for biomedicine applications.

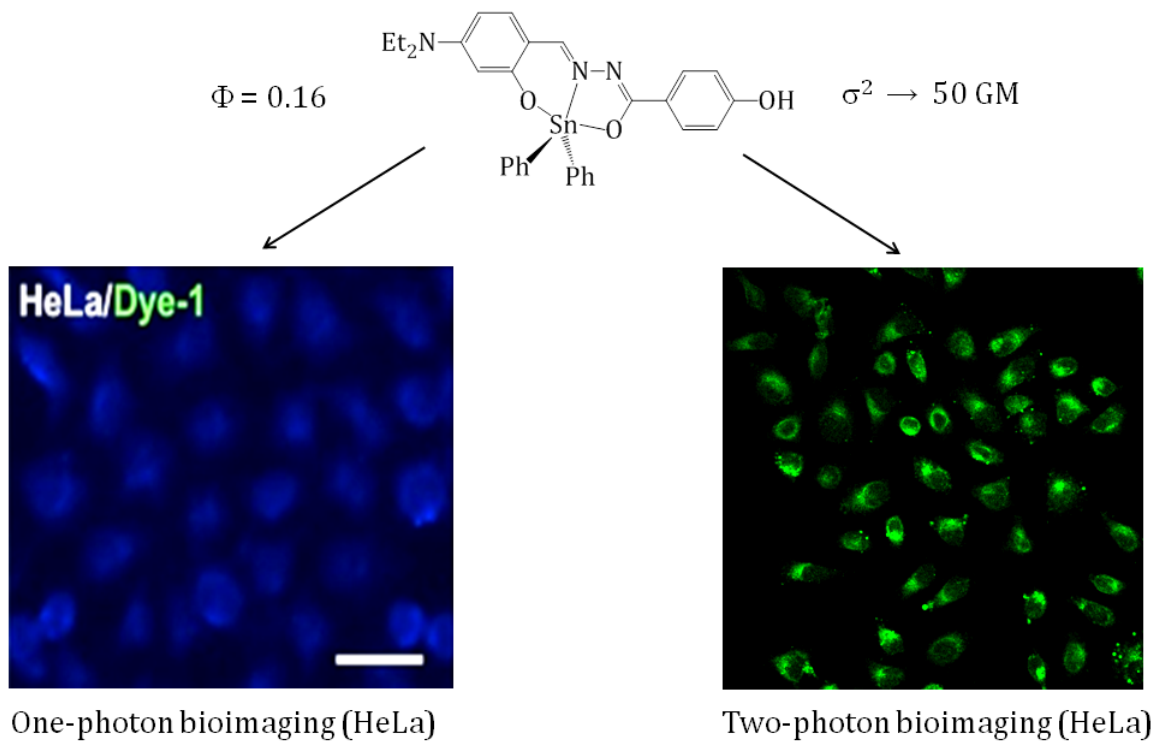

